\title{
GRITICAL STUDIES OF THE PYLORUS LIGATED RAT (SHAY RAT)
}

\author{
YASUO ISHII \\ Research Laboratories, Nippon Kayaku Co., Ltd. Shimo, Kita-ku, Tokyo \\ Received for publication September 13, 1968
}

The pylorus ligated rat (Shay rat) was described by Shay et al. (1) for the production of acute ulcers in the forestomach, and it has been also employed as a means of studying gastric secretion. This techniquc is now used extensively as a scrcening method of gastric secretory deprcssants and antipeptic ulcer agents (2-4) because of the following advantages: 1) the simplicity of surgical procedure, 2) the high ratc and rapid occurrence of ulccration, and 3) the possibility of mcasurements of gastric secretory rate and severity of ulceration in the samc animals; which make up for the shortcoming that ulcers are present only in the forestomach.

The pathogenesis of ulceration in the pylorus ligated rat has been discussed by many investigators, but the definite conclusion is not yet offered. Several factors have becn considered as causes of ulceration; such as the digestive effect of gastric juicc, the interfercnce of blood circulation or the decrease of mucosal resistance. Sun and Chen (5) concluded that the rumenal ulcers in the pylorus ligated rat might be merely a result of the volume and the concentration of gastric hydrochloric acid and pepsin upon the mucosa. But other factors can not be ruled out completely.

There remains some obscurities also in the gastric secretory mechanism of the pylorus ligated rat. It is often said that the pylorus ligated rat is inadequate for the estimation of stimulants of gastric sccrction, for they can hardly increase in gastric secretion in response to stimuli owing to the hypersecretion. The mechanism of the hypersecretion in the pylorus ligated rat is now still controversial.

The present study is an attempt to clarify the effects of various factors on gastric secretory rate and ulceration and to discuss the mechanisms of ulceration and gastric hypersecretion in the pylorus ligated rat.

\section{METHODS}

Male Donryu and Spraguc-Dawley rats weighing between 100 and $200 \mathrm{~g}$ (except where otherwise noted) were used for this study. They were maintained at $23^{\circ} \mathrm{C}$ and $60 \%$ humidity throughout the experiment. They were fasted for the fixed time in each cxperiment but were allowed free access to water, and weighed just prior to the surgical

Part of this study was presented at the 39th Annual Mecting of the Japanese Pharmacological Society at Kyoto (1966). 
operation. Under light ether anesthesia, the pylorus was ligated through a midline abdominal incision with care not to damage any blood vessels. After wound closure, the animals were caged individually without food and water during this period. At the end of experiments, the animals were sacrificed by exanguination and the stomachs werc removed. Gastric contents were drained from the stomach and centrifuged at 3,000 cps for 5 minutes, and the volume of supernatant solution was recorded. If the debris of gastric content was over $0.6 \mathrm{ml}$, the animal was excluded from the study because of possible contamination of the gastric contents by food residue or feces. Free and total acidities were estimated by titration with $0.1 \mathrm{~N} \mathrm{NaOH}$ using Töpfer and phenolphthalein as indicators. Acid output was expressed in $\mathrm{mEq}$ by multiplying the volume in $\mathrm{ml}$ by the acid concentration in $\mathrm{mEq} / \mathrm{l}$.

The pylorus ligated rat with acute fistula was prepared by the same surgical procedure to the pylorus ligated rat except the fixation of acute fistula made of polyethylenc tube at the forestomach. Immediately after the operation, the rats were placed in individual cages and the gastric juice was collected into the graduated centrifuge tube.

\section{RESULTS}

\section{Studies on rumenal ulceration}

1) Effect of various factors on ulceration

In order to study the various factors influencing the severity of ulcers, the experiment was designed using the orthogonal array of $L_{8}$. As shown in lablc 1, 4 factors consisting of 2 levels respectively, and 3 interactions between 2 factors were investigated. The cxperiment was repeated 4 times in the same design. The result was analysed according to the cummulative method devised by Taguchi (6). As the analytical value, the severity of ulceration was adopted, which was classified into the following 3 groups: ( $\cdots)$ no ulcer, $(+)$ unperforated ulcer and $(+)$ perforated ulcer. The results are shown in Tables 2 and 3 , which show that the strain of rat and the interaction between the time of starvation and the time after ligation are significant at $\mathrm{p}=0.01$, and the time of starvation and the time after ligation are significant at $p=0.05$. The body weight of the rat did not influence on the severity of ulceration. Namely, Donryu rats were more susceptible to ulceration than Sprague-Dawley rats, and the increase of the time of starvation to 2 days or the increase of the time after ligation to 19 hours augmented the severity of ulceration. Judg-

TABLE 1. Design of experiment on pylorus ligated rats using $\mathrm{L}_{8}$ orthogonal arrays.

\begin{tabular}{lll}
\hline \multicolumn{1}{c}{ Factor } & \multicolumn{1}{c}{ Level } \\
\cline { 2 - 3 } A : Strain & $\mathrm{A}_{1}:$ Donryu & \\
B : Body weight & $\mathbf{B}_{1}: 110-140 \mathrm{~g}$ & $\mathbf{B}_{2}: 160-190 \mathrm{~g}$ \\
C : Time of starvation & $\mathrm{C}_{1}: 48 \mathrm{hr}$ & $\mathrm{C}_{2}: 24 \mathrm{hr}$ \\
$\mathrm{D}:$ Time after ligation & $\mathrm{D}_{1}: 19 \mathrm{hr}$ & $\mathrm{D}_{2}: 19 \mathrm{hr}$ \\
$\mathbf{B} \times \mathrm{C}$ & & \\
$\mathbf{B} \times \mathbf{D}$ & & \\
$\mathrm{C} \times \mathrm{D}$ & & \\
\hline
\end{tabular}


TABLE 2. Analysis of variance of experiment on pylorus ligated rats using $\mathrm{L}_{8}$ orthogonal array.

\begin{tabular}{ccccc}
\hline Factor & $\begin{array}{c}\text { Degree of } \\
\text { freedom }\end{array}$ & $\begin{array}{c}\text { Sum of } \\
\text { square }\end{array}$ & $\begin{array}{c}\text { Mean } \\
\text { square }\end{array}$ & F \\
\cline { 3 - 5 } $\mathrm{A}$ & 2 & 13.35 & 6.68 & $10.19 * *$ \\
$\mathrm{~B}$ & 2 & 2.02 & 1.02 & 1.82 \\
$\mathrm{C}$ & 2 & 4.70 & 2.35 & $4.20^{*}$ \\
$\mathrm{D}$ & 2 & 6.51 & 3.25 & $5.81^{*}$ \\
$\mathrm{~B} \times \mathrm{D}$ & 2 & 0.68 & 0.34 & - \\
$\mathrm{B} \times \mathrm{D}$ & 2 & 0.51 & 0.25 & - \\
$\mathrm{C} \times \mathrm{D}$ & 2 & 8.04 & 4.02 & $7.18 * *$ \\
$\mathrm{e}$ & 48 & 28.18 & 0.59 & \\
\hline $\mathrm{T}$ & 62 & & & \\
$(\mathrm{e})$ & 52 & 29.37 & 0.56 & \\
\hline$* \mathrm{p}=0.05$ & $* * \mathrm{p}=0.01$ & & & \\
\hline
\end{tabular}

TABLE 3. The estimation of effects of factors showing significant difference at $\mathrm{p}=0.01$ or 0.05 .

\begin{tabular}{cccccc}
\hline Factor & \multicolumn{5}{c}{ Severity of ulcer } \\
& & - & + & $12(75.0 \%)$ & $16(100 \%)$ \\
$\mathrm{A}_{1}$ & $3(18.8 \%)$ & $1(6.2 \%)$ & 12 & Total \\
$\mathrm{A}_{2}$ & $5(31.3 \%)$ & $9(56.2 \%)$ & $2(12.5 \%)$ & $16(100 \%)$ \\
$\mathrm{C}_{1}$ & $2(12.5 \%)$ & $5(31.3 \%)$ & $9(56.2 \%)$ & $16(100 \%)$ \\
$\mathrm{C}_{2}$ & $6(37.4 \%)$ & $5(31.3 \%)$ & $5(31.3 \%)$ & $16(100 \%)$ \\
$\mathrm{D}_{1}$ & $7(43.7 \%)$ & $3(18.8 \%)$ & $6(37.5 \%)$ & $16(100 \%)$ \\
$\mathrm{D}_{2}$ & $1(6.3 \%)$ & $7(43.7 \%)$ & $8(50.0 \%)$ & $16(100 \%)$ \\
$(\mathrm{CD})_{1}$ & $1(6.3 \%)$ & $6(37.5 \%)$ & $9(56.2 \%)$ & $16(100 \%)$ \\
$\left(\mathrm{CDD}_{2}\right.$ & $7(43.7 \%)$ & $4(25.0 \%)$ & $5(31.3 \%)$ & $16(100 \%)$ \\
$\mathrm{C}_{1} \mathrm{D}_{1}$ & $1(12.5 \%)$ & $2(25.0 \%)$ & $5(62.5 \%)$ & $8(100 \%)$ \\
$\mathrm{C}_{1} \mathrm{D}_{2}$ & $1(12.5 \%)$ & $3(47.5 \%)$ & $4(50.0 \%)$ & $8(100 \%)$ \\
$\mathrm{C}_{2} \mathrm{D}_{1}$ & $6(75.0 \%)$ & $1(12.5 \%)$ & $1(12.5 \%)$ & $8(100 \%)$ \\
$\mathrm{C}_{2} \mathrm{D}_{2}$ & $0(0 \%)$ & $4(50.0 \%)$ & $4(50.0 \%)$ & $8(100 \%)$ \\
\hline
\end{tabular}

- : no ulcer + : unperforated ulcer + : perforated ulcer

ing from this result, the most appropriate condition as a scrcening mcthod of antipeptic ulcer agents is $A_{2}, C_{2}$ and $D_{2}$, which can produce unperforated ulcers at the highest rate. If a condition of Sprague-Dawley rats, $160-190 \mathrm{~g}$ of body weight, 24 hour starvation and 19 hour ligation are used, anticipated rates of ulcer production calculated by the omega method devised by Taguchi (6) are as follows: (-) $13.8 \%,(+) 70.2 \%$ and (t+) $16.0 \%$.

The difference of ulceration between strains may be not due to the difference of gastric secretory activity. Because the volumes of gastric juice in 6 hour pylorus ligated rats were $11.5 \pm 1.2 \mathrm{ml}$ in Donryu rats and $11.2 \pm 0.5 \mathrm{ml}$ in Sparague-Dawley rats and there was no significant difference between them.

2) Effect of glucose and protein hydrolysale on ulceration

Since the ulcerogenic effect of starvation was considered to be due to the decrease 
TARLE 4. Effect of administration of glucose and protein hydrolysate on ulceration in the pylorus ligated rats.

\begin{tabular}{|c|c|c|c|c|c|c|}
\hline \multirow{2}{*}{ Treatment } & \multirow{2}{*}{$\begin{array}{c}\text { Decrease of } \\
\text { body weight } \\
(\%)\end{array}$} & \multirow{2}{*}{$\begin{array}{l}\text { Severity } \\
\text { of ulcer }\end{array}$} & \multicolumn{4}{|c|}{ Gastric secretion } \\
\hline & & & $\begin{array}{l}\text { Volume } \\
(\mathrm{ml})\end{array}$ & $\mathrm{pH}$ & $\begin{array}{c}\text { Free acid } \\
(\mathrm{mEq})\end{array}$ & $\begin{array}{l}\text { Total acid } \\
(\mathrm{mEq} / 1)\end{array}$ \\
\hline \multirow{5}{*}{$\begin{array}{l}\text { Saline } \\
20 \mathrm{ml} / \mathrm{kg} \times 5 \\
\quad \text { (i.p.) }\end{array}$} & 19.6 & $+! t$ & - & - & - & - \\
\hline & 17.2 & + & 25.4 & 1.6 & 27 & 53 \\
\hline & 25.1 & + & 19.7 & 1.1 & 45 & 88 \\
\hline & 22.1 & HH & - & - & - & - \\
\hline & 21.7 & + & 19.8 & 1.3 & 34 & 66 \\
\hline Mean & 21.1 & & 21.6 & 1.3 & 35 & 69 \\
\hline \multirow{5}{*}{$\begin{array}{l}20 \% \text { Glucose } \\
\text { and } \\
5 \% \text { protein } \\
\text { hydrolysate } \\
10 \mathrm{ml} / \mathrm{kg} \times 5 \\
\text { (i.p.) }\end{array}$} & 19.1 & + & 19.9 & 1.5 & 30 & 56 \\
\hline & 16.9 & + & 21.1 & 1.2 & 41 & 71 \\
\hline & 19.8 & - & 15.9 & 1.2 & 43 & 72 \\
\hline & 19.8 & + & 19.9 & 1.0 & 67 & 110 \\
\hline & 20.1 & + & 24.2 & 1.3 & 40 & 63 \\
\hline Mean & 19.1 & & 20.2 & 1.4 & 44 & 74 \\
\hline
\end{tabular}

itt : Perforated ulcer + : Severe ulceration + : Slight ulceration -- : No ulcer

of mucosal resistance caused by undernourishment, the effect of administration of glucose and protein hydrolysate on ulceration was examined. The rats were treated with the intrapcritoneal injections of glucose $(2 \mathrm{~g} / \mathrm{kg})$ and protein hydrolysate $(10 \mathrm{ml} / \mathrm{kg}$ of $5 \%$ "Polytamin", Daigo-Eiyo-Kagagu Co., Ltd.) twice a day during 2 days of starvation and immediately after the ligation (5 times in total). The result is shown in Table 4.

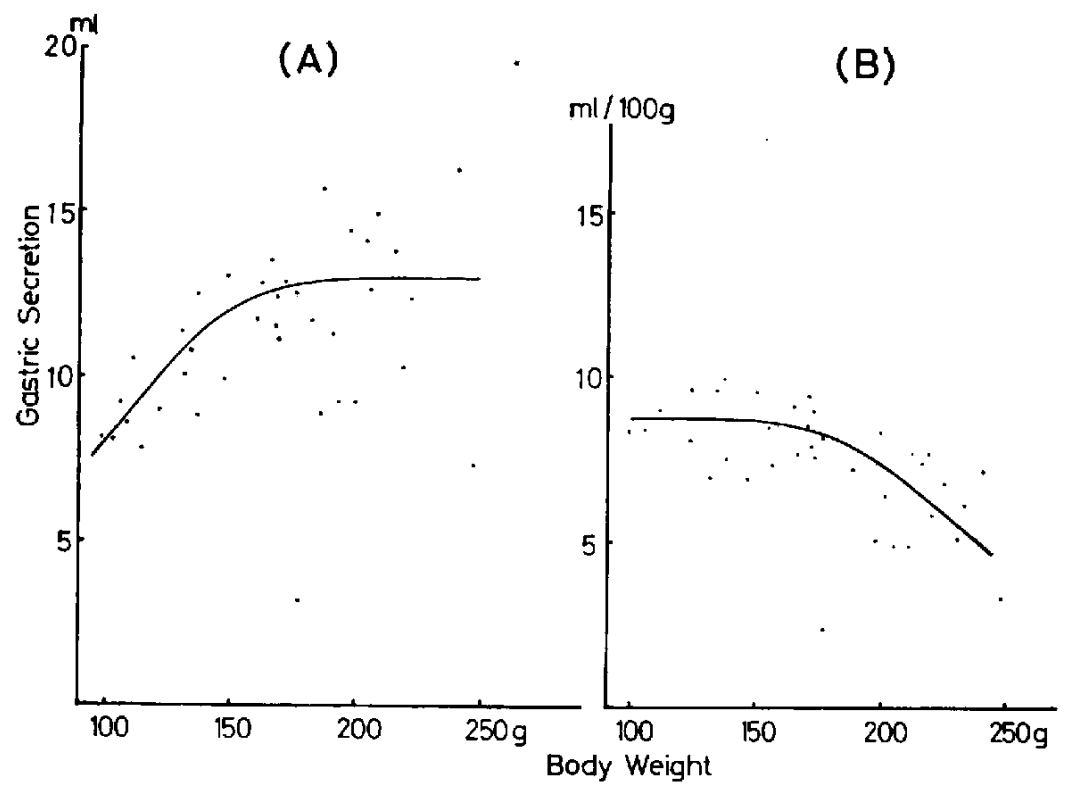

FiG. 1. The influence of body weight on the volume of gastric secretion in the 19 hour pylorus ligated rats. The volume of gastric secretion is expressed by $\mathrm{ml}$ per animal in (A) and by $\mathrm{ml}$ per $100 \mathrm{~g}$ body weight in (B). 
Though the decrease of body weight and the volume of gastric secretion of treated animals were not significantly different from those of controls, the severity of ulceration of treated animals was clearly low compared with controls.

II. Studies on gastric secretion

1) Influence of body weight on gastric secretion

The relationship between the volume of gastric secretion and the body weight of rats fasted for 48 hours was investigated in the 19 hour pylorus ligated rats. As shown in Fig. 1, a linear relationship between the volume of gastric secretion and the body weight within the 100 to $170 \mathrm{~g}$ was observed. Above those weights, the volume did not
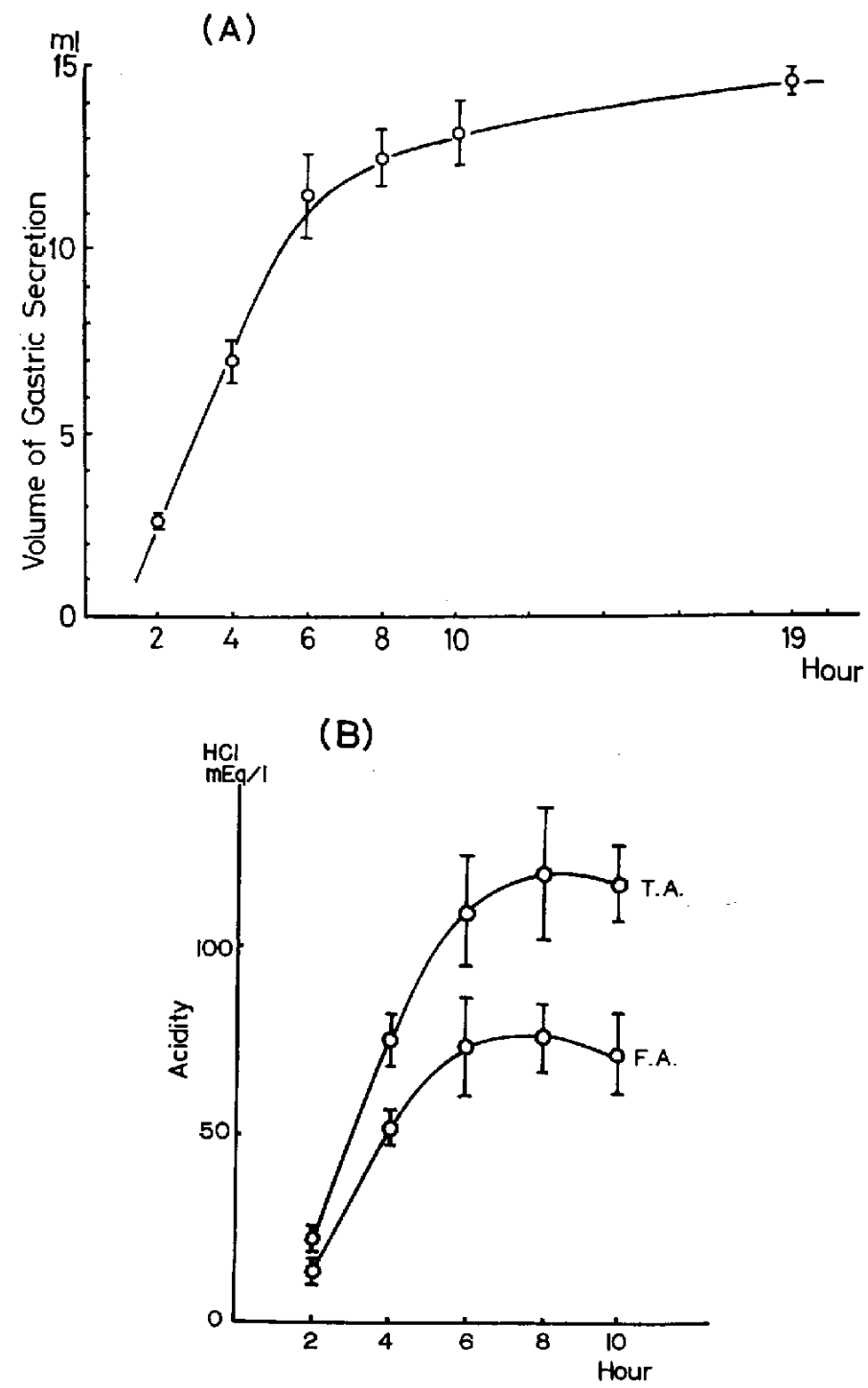

Fig. 2. The influence of time after pylorus ligation on gastric secretion.

(A) : Influence on volume of gastric secretion

(B) : Influence on free and total acidities of gastric secretion

Each point is a mean with standard error of 6 animals. 
increase with increasing body weight and the variance of it grew large.

2) Influence of the time after pylorus ligation

The influence of the time after pylorus ligation on the volume and acidity of gastric juice was studied in rats fasted overnight. As shown in Fig. 2 (A, B), a linear relationship between the volume or acidity and the time after pylorus ligation was observed within 6 hours, but above 6 hours the volume got nearly plateau and the free and total acidities slightly declined.

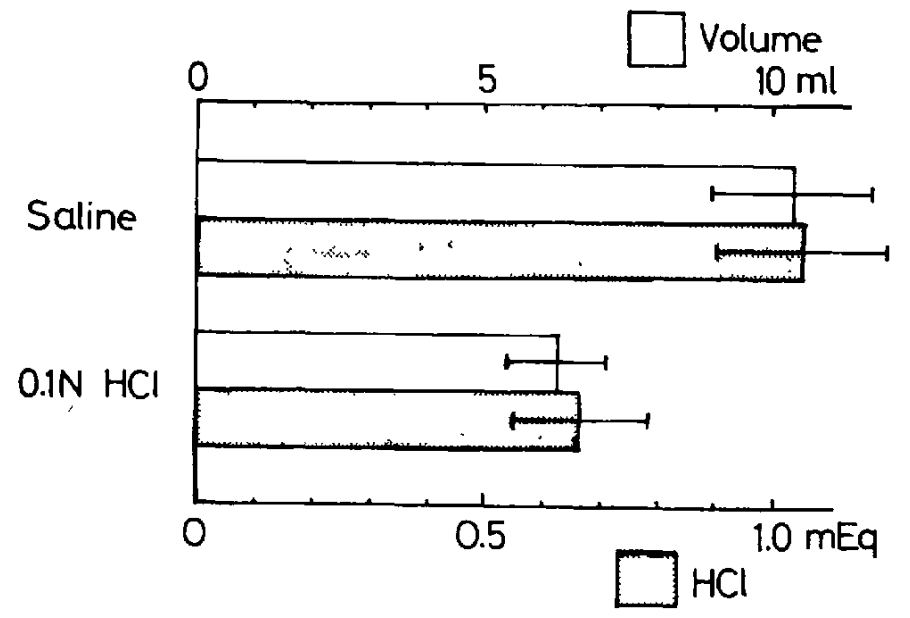

FIG. 3. The inhibitory effect of duodenal souring on gastric secretion in the 5 hour pylorus ligated rats. Each group consists of 5 animals.

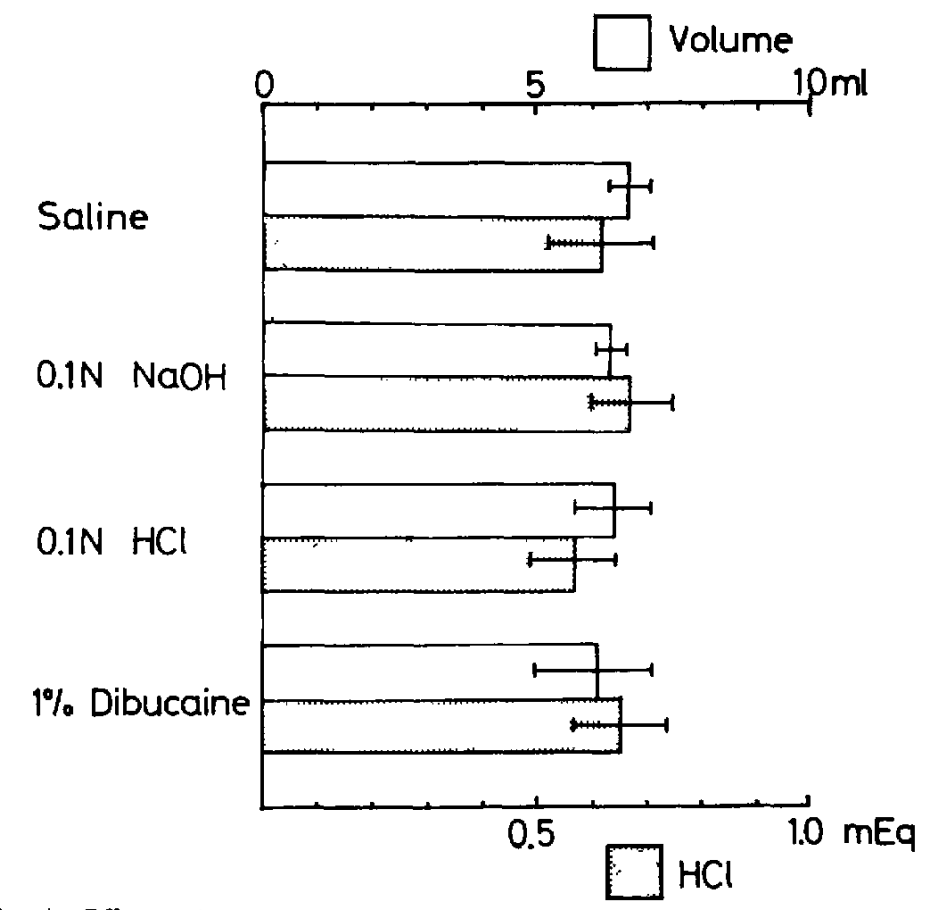

Fig. 4. Effects of acidification, alkalization or local anesthesia of stomach on gastric secretion in the 4 hour pylorus ligated rats. Each group consists of 6 animals. 
3) Effects of gastric or duodenal acidification, gastric alkalization and local anesthesia of gastric mucosa

These experiments were carried out in order to study the contribution of humoral stimulating mechanism of gastric secretion in the pylorus ligated rat. The effects of gastric acidification or alkalization and local anesthesia of gastric mucosa were investigated in the 4 hour pylorus ligated rats, and $1 \mathrm{ml}$ of $0.1 \mathrm{~N} \mathrm{HCl}, 0.1 \mathrm{~N} \mathrm{NaOH}$ or $1 \%$ dibucaine was injectd intragastrically after the pylorus ligation. The values of volume and acidity of gastric secretion were corrected for the values of injected solutions. For the purpose of studing the effect of duodenal acidification, $1 \mathrm{ml}$ of $0.1 \mathrm{~N} \mathrm{HCl}$ was injected immediately after the pylorus ligation in the 5 hour pylorus ligated rats. The results are summarized in Figs. 3 and 4. The injection of acid into the duodenum inhibited the gastric secretion, while the injections of acid, alkali or the local anesthetic into the stomach did not affect the gastric secretion.

\section{4) Gastric secretion in the pylorus ligated rats with acute fistula}

The relationship between the volume of gastric secretion and the time after pyloric ligation is shown in Fig. 5. The volume of gastric secretion increased in proportion to the time after ligation up to 10 hours. The total volume and the pattern of gastric secretion are apparently different from those of the pylorus ligated rats without acute fistula (refer to Fig. 2).

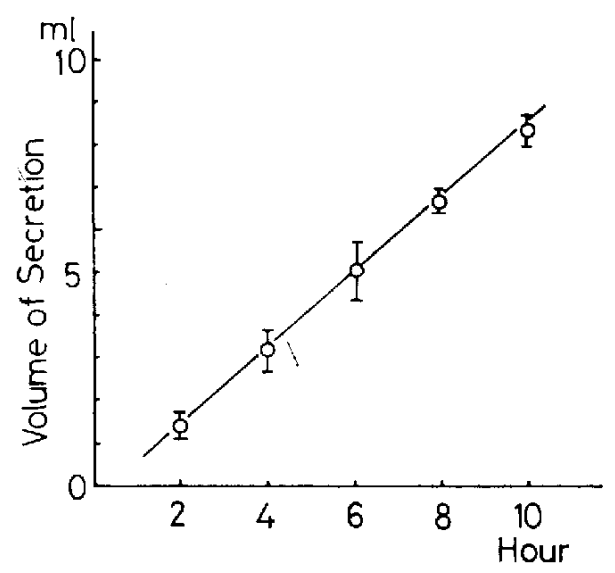

Fig. 5. The influence of time after pylorus ligation on gastric secretion in the pylorus ligated rats with acute fistula. Each point is a mean with standard error of 6 animals.

\section{DISCUSSION}

The etiology of ulceration in the pylorus ligated rats has been eagerly discussed, but the definitive conclusion is not yet given. The digestive action of gastric juice accumulated into the stomach is considered to be the primary cause of mucosal damages in the forestomach (5). In our present experiment using $\mathrm{L}_{8}$ orthogonal array, the time of starvation had a great influence on the severity of ulccration, which suggests that the undernutrition by starvation decreases the mucosal defense mcchanism and accelerates the ulcer production. The intraperitoneal administration of glucose and protein hydrolysate during starvation markedly prevented the ulcer production in the forestomach without any influence on body weight and gastric sccretion. Shay et al. (7) reported that the administration of high concentration of protein hydrolyzed products with normal foods prior to the starvation for 4 weeks decreased the ulcer production. These experiments show that the decrease of mucosal defense mechanism can not be neglected as the cause of ulceration in the pylorus ligated rats besides the accumulation of gastric juice in the stomach and 
obstruction of blood supply to the forestomach.

When the technique of the pylorus ligated rats is used as a screening method of antiulcer agents, unperforated ulcers should be produced at the highest rate because rats with perforated ulcer died before the end of experiments and precise information can not be obtained. In our experiment, a condition of Sprague-Dawley rats, 24 hour starvation and 19 hour pylorus ligation is considered to be most appropriate for this purpose.

The experimental data concerning gastric secretion in the pylorus ligated rats are conflicting, which may be due to the difference of analytical method of data. The volume of gastric juice in the pylorus ligated rat is often recorded as $\mathrm{ml}$ per $100 \mathrm{~g}$ rat body weight on the basis of the direct relationship between gastric secretion and body weight reported by Madden ef al. (8). In contrast, Brown et al. (3) described that the body weight had not any significant effect on the volume of secretion and therefore there was no necd to adjust for weight in expressing the volume of secretion. Our present result shows that there is a linear relationship between body weight and volume of secretion up to about $170 \mathrm{~g}$ body weight after overnight starvation, and above that weight the volume was nearly constant in spite of the increase of body weight and the variance grew large. Thereforc, as far as Donryu strain is concerned the rats weighing below $170 \mathrm{~g}$ after starvation should be used because of the small variance of values.

A linear relationship between the volume of secretion and the time after pylorus ligation within 6 hours and after that the volume of secretion was nearly plateau, which is slightly different from the result described by Sun et al. (5). The total and free acidities also got the maximum response at the 8 th hour after ligation. The time after pylorus ligation must be set within 8 hours for the study of gastric secretion.

It has becn usually difficult to demonstrate a substantial increase of a gastric acid output in good response to a gastric secretory stimulant, because the control value is high by itself and moreover the mechanism of the hypersecretion is not clear. Several opinions on the mechanism of the hypersecretion have been presented. Gati et al. (9) reported that the duodenal souring reduced the gastric secretory rate in the pylorus ligated rat, but Brodie (10) failed to ascertain this phenomenon. In our present cxperiment, the intraduodenal injection of acid decreased gastric secretion but the effect of gastic acidification, alkalization or mucosal anesthesia of the stomach on gastric secretion was not demonstrated. It shows that the humoral mechanism such as gastrin release has little effect on the hypersecretion in the pylorus ligated rat. Brodie (10) presumed that the mechanism of this hypersecretion was due to the stimulation of the pressure receptors in the antral mucosa by ligation. The present experiment shows that the volume and the pattern of gastric secretion of the pylorus ligated rat with acute fistula is different from those of the originally described pylorus ligated rats. This result is somewhat inconsistent with the conclusion of Brodie (10) and somewhat consistent with the suggestion of Levine (11) saying the possibility of the stimulation of gastric secretion by saliva. It may be reasonable to consider that the mechanism of hypersecretion in the pylorus ligated rat is very complicated and further investigations have to be carried out. 


\section{SUMMARY}

1. Various factors influencing the rumenal ulceration in the pylorus ligated rat were investigated using the experimental design of $\mathbf{L}_{\mathbf{s}}$ orthogonal array, and the most appropriate condition for the screening of antiulcer agents was presented.

2. The decrease of mucosal defense mechanism may be a cause of ulceration besides the peptic activity of gastric juice.

3. The relationship between the body weight of the rat and the volume of gastric secretion is linear between 100 to $170 \mathrm{~g}$ after starvation.

4. The volume and acidity of gastric juice increased in proportion to the gain of body weight up to 6 hours after pylorus ligation.

5. The duodenal souring suppressed the gastric secretory rate, but the humoral mechanism of gastric phase has little effect on it.

6. The pylorus ligated rat showed the hypersecretion and the mechanism of it may be complicated.

Acknowledgement: Valuable comments on the method of statistical analysis by Mr. W. Tanaka are gratefully acknowledged.

\section{REFERENCES}

1) Shax, H., Komarov, S.A., Fels, S.S., Merance, D., Grüenstein, M. and Siplet, H.: Gastroenterology $5,43(1954)$

2) Turner, R.A.: Screening Method in Pharmacnlogy, p. 221, Academic Press, London (1965)

3) Brown, D.M. And Turner, D.H.: Archs int. Pharmacodyn. Thér. 145, 489 (1963)

4) MoColl, J.D., Lee, C.F. And Hajou, A.: Archs inl. Pharmacodyn. Thér. 141, 181 (1963)

5) Sun, D.C.H. and Chrn, J.K.: Pathophysiology of Peptic Ulcer, p. 141, McGill University Press, Montreal (1963)

6) TAguchi, G.: Statistical Analysis (Japanese), p. 157, Maruzen, Tokyo (1967)

7) Silay, H., Greünstein, M., Siplet, H. and Komarov, S.A.: Proc. Soc. exp. Biol. Med. 69, 369 (1948)

8) Madden, R.J. and Ramsburg, H.H.: Gastroenterology 18, 128 (1951)

9) Gati, T., Gelencsér, F. and Srimfot, L.: Experientia 17, 218 (1961)

10) Brodie, D.A.: Am. J. Dig. Dis. 11, 231 (1966)

11) Levine, R.J.: Life Sci. 4, 959 (1965) 